\title{
Ağrı Devlet Hastanesine başvuran migren hastalarının klinik ve sosyodemografik özellikleri
}

\author{
Sociodemographic and clinical features of migraine patients admitted to Ağrı State \\ Hospital \\ Tuba Cerrahoğlu Şirin \\ Ağrı Devlet Hastanesi, Nöroloji Kliniği, Ağrı, Türkiye
}

\section{Öz}

Amaç: Migren, atak sırasındaki olumsuz etkilerinin yanı sıra okul ve iş performansında bozulmaya neden olarak sosyal açıdan kronik etkileri olan bir hastalıktır. Bu çalışmada, Ağrı ilinde migren tanısı alan ve takip edilen olguların sosyodemografik özellikleri ve sosyal yaşamdaki kısıtılık düzeylerinin araştırılması amaçlandı.

Gereç ve Yöntem: Nöroloji polikliniğine başvuran migren hastalarının dosyalarında demografik özellikleri, migren özellikleri, MIDAS skoru ve aylık baş ağrılı gün sayısı retrospektif olarak incelendi.

Bulgular: ICHD-3 kriterlerine göre migren tanısı alan 642 hasta (E/K:1/5) bulunmaktaydı. Yaş ortalaması 29.8 yıldı (7-71 yaş). Hasta popülasyonunda eğitim seviyesi düşükken (\%36 okuryazar değil, \%36 ilköğretim mezunu), çoğunluğunu ev hanımları oluşturmaktaydı (\%64). Baş ağrısı atakları başlangıcından migren tanısı alana kadar geçen süre ortalama $5.3 \mathrm{yıldı;} \mathrm{bununla} \mathrm{beraber,} \mathrm{eğitim} \mathrm{seviyesi} \mathrm{arttıkça} \mathrm{tanı} \mathrm{alma} \mathrm{zamanı} \mathrm{anlamlı} \mathrm{derecede}$ kısalıyordu $(p<0.01)$. Birinci derece akrabalarında migren öyküsü oldukça yüksekti $(\% 74)$. Hastaların \%21.7'inde auralı migren ve \%21.8'inde kronik migren vardı. Migren tetikleyicisi olarak en sık emosyonel stres (\%30) belirtildi. Migren Disabilite Değerlendirme (MIDAS) skorlarına göre şiddetli kayıp \%9.5 iken, orta derece kayıp \%27, ılımlı kayıp \%25.5 ve kayıp yok/hafif kayıp \%38 idi.

Sonuç: Eğitim süresi kısaldıkça migren hastalarında tanı alma süresi uzamaktadır. Kronik migren oranı yüksektir. Eğitim seviyesi düştükçe migren farkındalığının azalması bunun önemli bir etkeni olabilir. Eğitim seviyesi düşük toplumlarda hastalık farkındalığının arttırılması ile baş ağrısı nedenli sosyal yaşamdaki kısıtılığın azalması sağlanabilir.

Anahtar Sözcükler: Migren, sosyodemografik özellikler, klinik özellikler, Ağrı.

\section{Abstract}

Aim: The purpose of this study is to evaluate the sociodemographic features and social disability of the migraine patients in Ağrı.

Materials and Methods: Demographic features, migraine features, Migraine Disability Assessment (MIDAS) scores and days with headache per month of the migraine patients who admitted to neurology outpatient clinic were retrospectively evaluated.

Results: There were 642 migraine patients (M/F: 1/5) diagnosed by ICHD-III criteria. Average age was 29.8 years (7$71 \mathrm{yrs}$ ). The education level was low (36\% illiterate, 36\% primary school) and housewives formed the majority of the patients (64\%). The time period between beginning of the attacks and the diagnosis with migraine was 5.3 years on average; however, this period was significantly decreasing with higher education levels $(p<0.01)$. The percentage of first degree relatives of the patients with migraine history was very high with $74 \% .21 .7 \%$ of the patients had migraine with aura, whereas $\% 21.7$ of the patients had chronic migraine. The most frequent trigger of migraine was emotional stress (30\%). Severe disability was observed in $9.5 \%$ of the patients; $27 \%$ of the patients had moderate disability; $\% 25.5$ had mild disability and 38\% had minor/no disability depending on MIDAS scores.

Yazışma Adresi: Tuba Cerrahoğlu Şirin

Ağrı Devlet Hastanesi, Nöroloji Kliniği, Ağrı, Türkiye

Makalenin Geliş Tarihi: 27.06.2016 Kabul Tarihi: 01.11.2016 
Conclusion: Diagnose interval was longer in migraine patients with lower education level. Chronic migraine rate was higher. Decreased awareness of migraine in patients with lower education level may be the most important cause of these results. Decreasing the rate of social disability due to headache at lower educated societies may be achieved through increasing awareness towards migraine.

Keywords: Migraine, sociodemografic features, clinic features, Ağrı.

\section{Giriş}

Migren; nörolojik, gastrointestinal ve otonom değişikliklerin eşlik ettiği, primer epizodik bir baş ağrısı bozukluğudur. İnsanlık tarihi kadar eski bir hastalık olan migren, toplum için oldukça önemli bir sağlık sorunudur ve Dünya Sağlık Örgütü tarafından günlük yaşamda en çok kısıtııı yaratan hastalıklar arasında ele alınmaktadır. Baş ağrısı atakları okul ve iş performansında bozulmaya neden olarak sosyal açıdan kronik sorunlara neden olmaktadır. Bunun sonucu olarak, 41 milyon migren hastasının Avrupa'da tahmini maliyeti 27 milyar avrodur (1).

Çok sayıda çalışma migren prevalansını araştırmıştır. Prevalansın $\% 10$ ile $\% 16$ arasında değiştiği görülmektedir (2-5). Prevalanstaki farklılıkların nedeni; farklı sosyoekonomik grupların, farklı yöntemler (telefon ile görüşme, yüz yüze görüşme) aracılığıyla yapılmış çalışmalarla değerlendirilmiş olmasıdır. Migren baş ağrısının sosyodemografik özelliklerine yönelik Türkiye'de de çeşitli çalışmalar yapılmıştır. Diğer yandan, 2015 yılı Türkiye İstatistik Kurumu sağlık indeksinde son sırayı alan Ağrı ilinde migren baş ağrısının sosyodemografik özelliklerine yönelik bir çalışma mevcut değildir. Bu çalışmada, Ağrı ilinde nöroloji polikliniğine başvuran migren hastalarının sosyodemografik özellikleri ve sosyal yaşamdaki kısıtlılık düzeylerinin araştırııması amaçlanmıştır.

\section{Gereç ve Yöntem}

Bu çalışmada, hastanemiz nöroloji polikliniğine HaziranAralık 2015 tarihleri arasında başvuran tüm migren hastalarının tedavi izlemi için tutulan dosyaları geriye dönük olarak incelendi. Olgular demografik veriler, ek hastalık öyküleri, ailedeki migren öyküleri, migren özellikleri (migren alt tipi, aylık baş ağrılı gün sayısı, aylık atak sayısı, ağrı şiddeti, hastalık süresi, migren tetikleyicileri) ve Migren Disabilite Değerlendirme (MIDAS) skoru (6) açısından değerlendirildi. Migren tanısı için, Uluslararası Baş Ağrısı Derneği (IHS) Sınıflama Komitesi tarafından 2013 yılında yayınlanan Uluslararası Baş Ağrısı Sınıflaması III (ICHD III) kriterleri kullanıldı (7). Üç aydan uzun süre, ayın en az 15 gününde ve ayda en az 8 gün migren özelliği taşıyan baş ağrısı olması kronik migren olarak tanımlandı. 6 aylık zaman periyodunda ICHD-III kriterlerine göre migren tanısı alan 737 hasta bulunmaktaydı. 95 hasta, dosyalarındaki eksik veriler nedeniyle çalışma dışı bırakıldı. Çalışmaya 642 hasta dahil edildi.
İstatistiksel değerlendirme SPSS 22.0 (SPSS Inc. Chigaco, USA) kullanılarak yapıldı. Kategorik verilerin karşılaştırması için ki-kare testi, non-parametrik değerler için Mann Whitney $U$ testi, non-parametrik değerlerin arasındaki ilişkinin gücünü değerlendirmek için Spearman Rho testi, sayısal bağımsız verilerin karşılaştırılmasında Student-t testi kullanıldı. Tüm testler için $p<0.05$ değeri anlamlı kabul edildi.

\section{Bulgular}

Çalışmamıza dahil edilen 642 hastanın \%83'ü $(n=535)$ kadın, \%17'si ( $n=107)$ erkekti. Ortalama yaş $29.8 \pm 11.7$ (7-71 yaş) yıl olarak saptandı. Olguların \%13.7'si ( $n=88)$ 17 yaş ve altındayken, olguların \%64.2'si $(n=412)$ 18-39 yaş aralığında kümelenmişti. Her iki cinsiyette de 40 yaş üstündeki hasta oranı, 40 yaş altı hasta oranına kıyasla azalmıştı. Auralı migren tüm olguların \%21.7'sinde ( $n=139)$ saptandı, kadın ve erkek cinsiyet arasında anlamlı farklılık yoktu. Migren ağrısı varlığı süresi ortalama 6.1 yıldı. Olguların çoğu düşük eğitim seviyesine sahipti (\%36 okuryazar değil, \%36.8 ilköğretim mezunu) ve başvuruların çoğunluğunu ev hanımları oluşturmaktaydı (\%64.3) (Tablo-1).

Olguların birinci derece akrabalarında migren öyküsü yüksek oranda (\%74) mevcuttu. Birinci derece akrabalarında migren öyküsü olan hasta oranı, auralı migren hastalarında benzerken (\%74.8), 18 yaş altı hastalarda daha da yüksekti (\%94.3) (Tablo-1). Birinci derece akrabada migren öyküsü olan ve olmayan hastalar arasında, migrenin başlangıç yaşı açısından anlamlı farklılık saptanmadı $(\mathrm{p}=0.28)($ Tablo-2).

Olguların migren ataklarının başlangıcından migren tanısı alana kadar geçen süre ortalama 5.3 yıldı. Okuryazar olmayanlarda tanı alma süresi daha uzunken (ortalama 7.9 yıl), eğitim seviyesi arttıkça tanı alma süresi (yüksek öğrenim mezunlarında ortalama 2.8 yıl) kısalmaktaydı (Tablo-3). Eğitim süresi ile tanı alma süresi arasındaki ilişki istatistiksel olarak anlamlıydı $(p<0.01)$. On sekiz yaş altı hastalarda ilk tanı alma süresi ortalama 2.1 yıldı.

Tüm hasta popülasyonundaki bir aydaki baş ağrılı gün sayısı ortalama $7.7 \pm 6.8$ gündü. Hastaların \%66.9'unda $(n=430)$ ayda 4 günden fazla baş ağrısı şikayeti mevcuttu. ICHD-III kriterlerine göre değerlendirildiğinde hastaların \%21.8'inde kronik migren vardı. MIDAS skorlarına göre ciddi kayıp \%9.5 iken, orta derece kayıp \%27, ılımlı kayıp \%25.5 ve kayıp yok/hafif kayıp \%38 idi. Atak şiddeti hastaların \%80'inde şiddetli/çok şiddeti olarak belirtildi (Tablo-4). Boy-kilo indeksi ve çocuk 
sayısı ile MIDAS skorları arasında anlamlı istatistiksel ilişki saptanmadı (sırasıyla $p=0.13$ ve $p=0.07$ ).

Migren tetikleyici faktörler arasında en sık neden emosyonel stres olarak tanımlandı (\%30). İkinci sırada sigara ve tandır dumanı maruziyeti izlendi (\%23). Diğer tetikleyici nedenler, uyku problemleri (\%22), açlık (\%6.6), çeşitli yiyecekler (\%4.3), hava değişimi (\%2.8), parlak ışık (\%1.8) ve koku $(\% 0.7)$ olarak sıralandı. Kadınlarda en sık migren tetikleyicisi emosyonel stresken (\%31), erkeklerde ise birinci sırada duman maruziyeti (\%73) vardı (Şekil-1).

Tablo-1. Çalışmaya Alınan Hastaların Sosyodemografik Özellikleri.

\begin{tabular}{|c|c|c|c|}
\hline & Toplam (\%) & Kadın (\%) & Erkek (\%) \\
\hline Hasta sayısı & $642(100 \%)$ & $535(83 \%)$ & $107(17 \%)$ \\
\hline Ortalama yaş/yıl & $29.8 \pm 11.7$ & $30 \pm 11.7$ & $29.1 \pm 11.7$ \\
\hline Auralı migreni olan olgular & $139(21.7 \%)$ & $116(21.7 \%)$ & $23(21.5 \%)$ \\
\hline Aurasız migreni olan olgular & $503(78.3 \%)$ & $419(78.3 \%)$ & $84(78.5 \%)$ \\
\hline Yaş dağılımı & Toplam (\%) & Kadın (\%) & Erkek (\%) \\
\hline 18 yaş altı & $88(13.7 \%)$ & $69(10.7 \%)$ & $19(3 \%)$ \\
\hline $18-29$ yaş & $260(40.5 \%)$ & $218(34 \%)$ & $42(6.5 \%)$ \\
\hline 30-39 yaş & $152(23.7 \%)$ & $127(19.8 \%)$ & 25 (3.9\%) \\
\hline $40-49$ yaş & $102(15.9 \%)$ & $85(13.2 \%)$ & $17(2.6 \%)$ \\
\hline 50 yaş üstü & $40(6.2 \%)$ & $35(5.5 \%)$ & $5(0.8 \%)$ \\
\hline Ailede migren olan & Toplam (\%) & Kadın (\%) & Erkek (\%) \\
\hline 17 yaş ve altı & $83(\% 94.3)$ & $65(\% 16.2)$ & $18(\% 24.3)$ \\
\hline 18 yaş üstü & $392(\% 70.7)$ & $336(\% 83.7)$ & $56(\% 75.6)$ \\
\hline Auralı migren & $104(\% 74,8)$ & $88(\% 84.6)$ & $16(\% 15,3)$ \\
\hline Tüm hastalarda & $475(\% 74)$ & $401(\% 62.4)$ & $74(\% 11.6)$ \\
\hline Öğrenim durumu & Toplam (\%) & Kadın (\%) & Erkek (\%) \\
\hline Okuryazar değil & $232(36.1 \%)$ & 227 (42.4\%) & $5(4.7 \%)$ \\
\hline İlköğretim & $236(36.8 \%)$ & $192(35.9 \%)$ & $44(41.1 \%)$ \\
\hline Lise & $109(17 \%)$ & $71(13.3 \%)$ & 38 (35.5\%) \\
\hline Yükseköğretim & $65(10.1 \%)$ & $45(8.4 \%)$ & $20(18.7 \%)$ \\
\hline Meslek & Toplam (\%) & Kadın (\%) & Erkek (\%) \\
\hline Ev kadını & $413(\% 64.3)$ & $413(\% 77.1)$ & $0(\% 0)$ \\
\hline Öğrenci & $150(\% 23.3)$ & $113(\% 21.1)$ & 37 (\%34.5) \\
\hline Ücretli çalışan & $42(\% 6.5)$ & 7 (\%1.3) & 35 (\%31.7) \\
\hline Diğer & $37(\% 5.7)$ & $2(\% 0.03)$ & 35 (\%31.7) \\
\hline
\end{tabular}

Tablo-2. Ailede Migren Öyküsü Olup Olmaması ile Migren Başlangıç Yaşı Arasındaki Ilişki.

\begin{tabular}{lcccc}
\hline & Tüm hastalar & $\begin{array}{c}\text { Ailede migren } \\
\text { öyküsü var }\end{array}$ & $\begin{array}{c}\text { Ailede migren } \\
\text { öyküsü yok }\end{array}$ & p \\
\hline Migren başlangıç yaşı (ortalama yıl) & 23.6 & 23.2 & 24.8 & NS* $^{*}$ \\
Migren varlığı (ortalama yıl) & 6.1 & 6.3 & 5.8 & NS* $^{*}$ \\
\hline
\end{tabular}

NS: Anlamlı değil.

Tablo-3. Eğitim Durumu ile Migren Baş Ağrılarının Başlangıcından Migren Tanısı Almaya Kadar Geçen Süre.

\begin{tabular}{lcc}
\hline & Tanı almaya kadar geçen süre (ortalama yıl) & $\mathbf{p}$ \\
\hline Tüm hastalar & 5.3 & \\
Okuryazar değil & 7.9 & $\mathrm{p}<0.01$ \\
İlköğretim mezunu & 4 & \\
Lise mezunu & 3.8 & \\
Yükseköğretim mezunu & 2.8 & \\
\hline
\end{tabular}




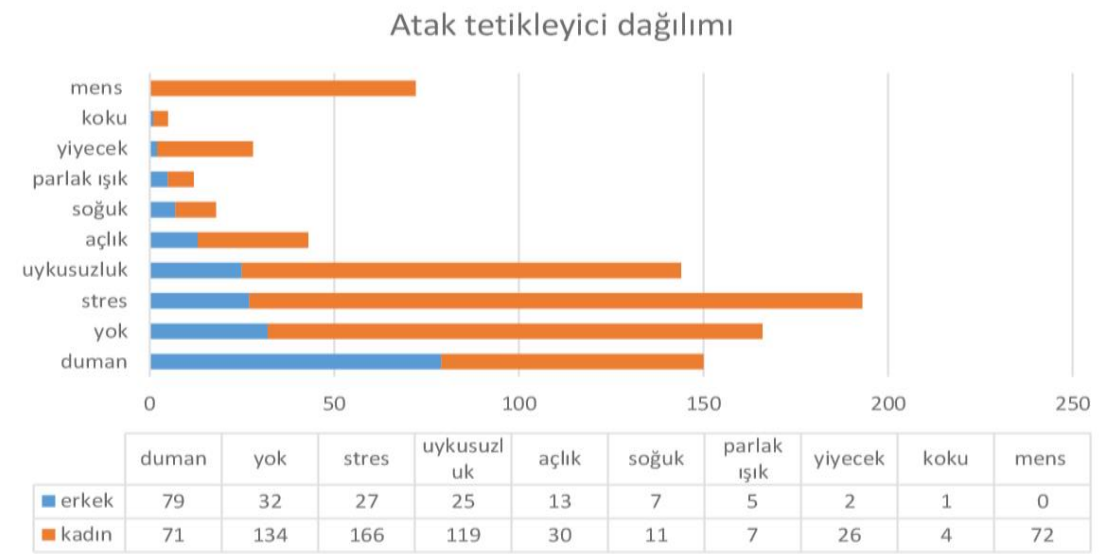

Şekil-1. Migren ataklarını tetikleyici etkenlerin cinsiyetle ve toplam hastalarda dağılımı.

Tablo-4. Hastaların Ortalama Baş Ağrılı Gün Sayısı, Atak Şiddeti ve MIDAS Skorları.

\begin{tabular}{|c|c|c|c|c|}
\hline Baş ağrılı gün & Kadın & Erkek & $\mathbf{p}$ & Toplam \\
\hline Aylık baş ağrılı gün sayısı (ort. $\pm S D$ ) & $8.0 \pm 6.9$ & $62 \pm 6.0$ & $\mathrm{NS}^{*}$ & $7.7 \pm 6.8$ \\
\hline Son 3 ayda, Aylık $\geq 15$ gün baş ağrısı (\%) & 22.90 & 15.80 & $\mathrm{NS}^{*}$ & 21.80 \\
\hline Atak şiddeti (\%) & Kadın & Erkek & $\mathbf{p}$ & Toplam \\
\hline Sıklıkla hafif & 2 & 5 & & 2 \\
\hline Sıklıkla orta & 17 & 20 & $\mathrm{NS}^{*}$ & 17.70 \\
\hline Sıklıkla şiddetli & 55 & 49 & & 53.80 \\
\hline Sıklıkla çok şiddetli & 26 & 26 & & 16.90 \\
\hline MIDAS (\%) & Kadın & Erkek & $\mathbf{p}$ & Toplam \\
\hline Hiç kayıp yok/çok az & 35.30 & 50.40 & & 38 \\
\hline Hafif kayıp & 24.40 & 47.10 & $\mathrm{NS}^{*}$ & 25.50 \\
\hline Orta derece kayıр & 29.10 & 16.80 & & 27 \\
\hline Ciddi kayıp & 12.20 & 6.50 & & 9.50 \\
\hline
\end{tabular}

NS: Anlamlı değil.

\section{Tartışma}

Migren genel popülasyonda yüksek prevalansta görülmesi nedeniyle hastalar ve yakınları kadar toplumu da ilgilendiren düzeyde maluliyete neden olan bir hastalıktır. Dünya çapında baş ağrılı erişkinlerde migren \%10 ve aylık 15 günden fazla baş ağrısının görüldüğü kronik migren \%3 olarak bulunmuştur (8). Kronik migrenin hastaların baş ağrısı ilişkili maluliyetini arttırdığı, daha kötü sosyoekonomik duruma, azalmış sağlıkla ilişkili yaşam kalitesine ve artmış sağlık harcamalarına neden olduğu gösterilmiştir (9).

Çalışmamız Ağrı ilinde migren ile ilgili yapılmış ilk çalışmadır. Ağrı il merkezinde tek hastane olması ve ilçe hastanelerinde genelde nöroloji uzmanı bulunmaması nedeniyle nörolojik problemleri olan hastalar hastanemiz nöroloji kliniğine başvurmaktadır; ancak genel olarak sosyoekonomik düzeyin düşük olması ve uzun süren kış şartları dolayısıyla hastaneye ulaşım zorlukları sonucunda çalışmamızın il bazında genel popülasyondaki migren sıklığını yansıtamadığı düşünülmektedir.
Nöroloji polikliniğimize başvuran 642 migren hastasının \%83'ü kadın cinsiyetteydi. Dünyada ve Türkiye'de yapılan migren prevalans çalışmalarında benzer şekilde hastaların çoğunluğunun kadın olduğu tespit edilmiştir (3,10-12). Migren prevalansının kadınlarda, özellikle doğurganlık döneminde artış gösterdiği izlenmektedir ve bu durum hormonal değişimler ile açıklanmaktadır (13). Avrupa'da migren prevalansına yönelik meta-analiz verileri, migrenin kadınlarda erkeklere kıyasla 2-3 kat daha sık olduğu yönündedir (5). Çalışmamızda erkek/kadın oranı 1:5'ti. Üreme yaş grubunda migren oranının kadın yönüne kaydığı bilinmektedir (14). Çalışmamıza alınan hastaların çoğunluğunu üreme çağındaki kadınlar oluşturmuş olduğu için erkek/kadın oranının Avrupa çalışmalarına kıyasla yüksek çıktığı düşünülmüştür.

Çalışmamızda, ICHD-III kriterlerine göre değerlendirilen auralı migren sıklığı önceki çalışmalara benzerdir $(2,10,12)$. Her iki cinsiyet ve tüm yaş gruplarında migren görülmekle beraber, diğer migren prevalans çalışmalarına benzer şekilde çalışmamızda da üreme çağındaki kadınlarda prevalans daha yüksekti (5). 
Kadın migrenlilerin \%77'si, tüm migrenlilerin ise \%64'ü ev kadınıydı. Kadın hastaların yarıya yakını (\%42.4) okuryazar değildi ve \%35.9'u ilköğretim mezunuydu. Tüm hastalar içinde lise ve yükseköğretim mezunları ancak \%27 oranındaydı. Çalışmamızda, sosyokültürel düzeyi düşük hasta popülasyonunda eğitim süresi arttıkça migren tanısı alma süresinin istatistiksel olarak anlamlı derecede kısaldığını tespit ettik. Benzer olarak, bazı çalışmalarda migren prevalansının düşük eğitim seviyesi ve düşük ekonomik durum ile ilişkili olarak arttığı gösterilmiştir (14,15). Bunun aksine, bazı çalışmalar yüksek entelektüel seviye ve sosyal statünün artmış migren prevalansıyla ilişkili olduğunu öne sürmektedir (2,3,10,12,16-18). Migren prevelansının ekonomik durum ve eğitim seviyesiyle herhangi bir ilişkisi olmadığını öne süren çalışmalar da bulunmaktadır $(4,8,19)$. Eğitim seviyesi arttıkça migren sıklığının arttığını ortaya koyan çalışmalarda, eğitim seviyesinin artmasıyla beraber bir çalışmaya katılmaya gönüllü olma oranının artmış olması etkili olmuş olabilir. Ayrıca yüksek eğitim seviyesi ile beraber artan migren semptom algısı ve doktor başvurusu ile de ilişkili olabileceği de göz önünde bulundurulmalıdır. Düşük sosyokültürel düzeyde migren hayatı tehdit eden sonuçlarının olmaması nedeniyle doktora başvuru açısından gerekli önemi görmüyor olabilir. Yine de baş ağrısı ataklarının işe devamı engellemesi nedeniyle sosyal hayatta ve iş hayatında kısıtlılığa neden olmaya devam etmektedir.

Migren, genetik yatkınlık gösteren ve ailesel geçiş eğilimi olan bir hastalıktır. Ailede migren öyküsü \%45-70 oranında görülebilir (20). Çalışmamızda, Doğu Anadolu'da yapılan önceki çalışmalara benzer şekilde, hastaların birinci derece akrabalarında migren görülme oranı yüksek (\%74) bulunmuştur $(10,12)$. Russell ve ark. (21), aurasız grup ile karşılaştırıldığında, auralı migren hastalarının birinci derece akrabalarında migren öyküsünün daha fazla olduğunu (genel popülasyona kıyasla auralı migrende 4 kat; aurasız migrende 1.9 kat artmış risk) bildirmiştir. Ancak çalışmamızda iki grubun ailedeki migren öyküsü sıklığında belirgin fark izlenmedi. Ailede migren öyküsü olan bireylerde hastalığın erken yaşta başlangıç gösterdiğine dair çalışmalar da mevcut olmakla beraber, bizim çalışmamızda anlamlı bir ilişki saptanmamıştır $(22,23)$.

Baş ağrısının oluşmasında predispozan faktörlerin stres, mental gerilim, mensturasyon, alkol, hava değişikliği, bazı gıdalar ve sigara içilmesi olduğu literatürde gösterilmektedir (19,24). Çalışmamızda emosyonel stresin, hem tüm hasta popülasyonu genelinde, hem de kadın popülasyonda migren atağını tetikleyen başlıca faktör olduğu izlendi. İkinci sırada ise duman teması yer aldı. Erkeklerde duman temasının migren atağını tetikleyen en belirgin faktör olduğu izlendi. Kelman'ın (24), migren tetikleyicilerini araştırdığı çalışmasında ilk sırayı stres alırken, tetikleyiciler arasında duman maruziyeti alt sıralarda ve \%35 oranında yer aldığını bildirmiştir. Bölgede ekmek yapımında odun ateşinde tandır kullanılması ve yaygın şekilde sigara içilmesi nedeniyle tetikleyiciler arasında duman maruziyetinin üst sıralarda yer aldığı düşünüldü. Hava değişimi gibi faktörlerden kaçınabilmek mümkün değildir ancak duman teması kaçınılabilecek bir migren tetikleyicisidir. Hastalık kontrolünü kolaylaştırmak ve ilaç kullanımını azaltmak adına duman gibi özgül tetikleyicilerden kaçınmak gerektiği konusunda bölge halkını bilinçlendirmek ağrı sıklığını azaltmak konusunda yardımcı olacaktır.

Migren hastalarının yarısında yatak istirahati gerektirecek veya ciddi iş gücü kaybına neden olacak şiddetli ağrılar vardır ve bu hastalarında yarısında da iş veya okulda üretkenlik etkilenmiştir (14). Özdemir ve ark (3), Erzurum'da MIDAS'a göre \%37.8 derece I, \%20.7 derece II, \%23.2 derece III ve \%18.3 derece IV kayıp bildirmiştir. Çalışmamızda MIDAS skorlarına göre Özdemir'in çalışmasına kıyasla şiddetli kayıp daha azdı, orta ve ılımlı derece kayıp alanında hasta yoğunluğu vardı. Hasta dağılımında şiddetli kayıp \%9.5 iken; \%27 derece III, \%25.5 derece II ve \%38 derece I şeklindeydi. Çalışma sonuçlarında farklar olmasına rağmen, migren atakları yaşam kalitesinin azalması ve iş gücü kaybına neden olmaktadır. Bunun sonucu olarak ortaya çıkan üretkenlik azalması sosyoekonomik yüke yol açmaktadır.

Migren, dünya çapında geçici maluliyetin en sık nedenidir bununla beraber doktora başvuru \%70 oranındadır (2). Şiddetli baş ağrısı olan migren hastalarının \%40'ı ve ayda 4'ten fazla atak geçiren hastaların \%47.8'i hiç doktora başvurmamıştır (2). Çalışmamızda, hastalarımızın aylık baş ağrılı gün sayısı önceki çalışmalara benzerdir. Atak şiddeti hastalarımızın \%80'inde şiddetli/çok şiddetli olarak belirtilmiştir ve başvuruların \%66.9'unda baş ağıılı gün sayısı 4 ve üzerindedir. Aygül ve ark. (12) Doğu Anadolu'da yaptığı çalışmada şiddetli ağrısı ile başvuran hasta oranı yüksek saptamıştır (\%75) ve eğitim seviyesi daha yüksek olan grubun \%25'inde ayda 3'ten fazla atak gözlemiştir (12). $\mathrm{Bu}$ durum, bizim hasta popülasyonumuz olan eğitim seviyesi düşük hastaların nöroloji polikliniğine başvuru için çok sayıda ve şiddetli ağrı olmasını beklediği ve daha hafif atakları için başvurmadığını düşündürmektedir.

Amerikan Migren Prevelans ve Korunma çalışmasında, migren hastaları arasında kronik migren sıklığı \%7,6 olarak bildirilmiştir (25). Çalışmamızda, kronik migren sıklığı oldukça yüksek (\%21.8) saptanmıştır. Norveç'te Hagen ve ark. (26) 22718 katılımcı ile yaptığı prospektif çalışmada, düşük sosyoekonomik düzeyi takiplerde artış gösteren kronik baş ağrısı ile ilişkili bulmuştur. Manack ve ark. (27) çalışması da kronik migren ve düşük gelir seviyesi ilişkisini desteklemektedir. Ağrı ili, 2015 Türkiye istatistik kurumu verilerine göre gelir ve servet indeksinde 81 il arasında 80. sırada, sağlık indeksinde 
ise son sırada yer almıştır (28). Genel olarak sosyoekonomik düzeyi düşük olan bu ilde sağlık kuruluşuna yeterli başvuru olmaması, tanı alma süresinin gecikmesi ve takiplerin aksatılması nedeniyle yeterli proflaktik tedavinin alınamıyor olmasının kronik migren sıklığındaki artışın nedeni olabileceği düşünülmektedir.

\section{Sonuç}

Ağrı ilinde polikliniğe başvuran migren olgularını incelediğimiz çalışmamızda; sosyodemografik özelliklerin, Türkiye'de ve Avrupa'da daha önce yapılan çalışmalara benzerlik gösterdiği izlenmiştir. Hastaların çoğunluğu üreme çağındaki kadınlar oluşturmaktaydı. Hem auralı hem aurasız migren hastalarının birinci derece akrabalarında migren öyküsü fazlaydı, iki grup arasında anlamlı farklılık yoktu. Bununla beraber, hastalarımızın eğitim süresi kısaldıkça migren tanısı alma süresinin uzamış olması ve kronik migren sıklığının yüksek olması çalışmanın en çarpıcı özellikleri olmuştur. Kronik migren sıklığının artmış olması yanı sıra başvuruların büyük çoğunluğunun şiddetli baş ağrılarının oluşturduğu dikkat çekmiştir. Eğitim seviyesi düşük bir toplumda kronik migren sıklığının artması daha erken süreçte tanı ve uygun proflaktik tedavi alınamamasına yorulabilir. Bu nedenle migren ataklarının iş gücü kaybına neden olması ve yapılan sağlık harcamaları yönünden ülke ekonomisine yük getirmesi nedeniyle düşük sosyokültürel popülasyonda migren farkındalığının arttırılması önemlidir.

\section{Kaynaklar}

1. Andlin-Sobocki P, Jonsson B, Wittchen HU, Olesen J. Cost of disorders of the brain in Europe. Eur J Neurol 2005;12(Suppl 1):1-27.

2. Ertas M, Baykan B, Orhan EK et al. One year prevalence and the impact of migraine and tension-type headache in Turkey: A nationwide home-based study in adults. J Headache Pain 2012;13(2):147-57.

3. Özdemir G, Aygül R, Demir R, Özel L, Ertekin A, Ulvi H. Migraine prevalence, disability, and sociodemographic properties in the eastern region of Turkey: A population-based door-to-door survey. Turk J Med Sci 2014;44(4):624-9.

4. Börü UT, Kocer A, Lüleci A, Sur $H$, Tutkan $H$, Atli H. Prevalence and characteristics of migraine in women of reproductive age in Istanbul, Turkey: A population based survey. Tohoku J Exp Med 2005;206(1):51-9.

5. Stovner LJ, Andree C. Prevalence of headache in Europe: A review for the Eurolight project. J Headache Pain 2010;11(4):289-99.

6. Ertaş M, Siva A, Dalkara T, et al. Validity and reliability of the Turkish Migraine Disability Assessment (MIDAS) questionnaire. Headache 2004;44(8):786-93.

7. Headache Classification Committee of the International Headache Society (IHS). The International Classification of Headache Disorders, 3rd ed. (beta version). Cephalalgia 2013;33(9):629-808.

8. Jensen R, Stovner LJ. Epidemiology and comorbidity of headache. Lancet Neurol 2008;7(4):354-61.

9. Adams AM, Serrano D, Buse DC et al. The impact of chronic migraine: The Chronic Migraine Epidemiology and Outcomes (CaMEO) Study methods and baseline results. Cephalalgia 2015;35(7):563-78.

10. Aygül R, Deniz O, Güzelcik M, Şahin A. Migrenli hastaların sosyodemografik özellikleri. Atatürk Üniversitesi Tıp Fakültesi Dergisi 2001;33:91-6.

11. Cakmak G, Yayla V, Muhan A, Gulersonmez M, Apak I. Sociodemographic evaluation of patients with migraine. Brain and Vascular Diseases Magazine 1996;2(1):29-31.

12. Aygul R, Deniz O, Kocak N, Orhan A, Ulvi H. The clinical properties of a migraineuse population in Eastern Turkey-Erzurum. South Med J 2005;98(1):23-7.

13. MacGregor EA. Oestrogen and attacks of migraine with and without aura. Lancet Neurol 2004;3(6):354-61.

14. LiptonRB, Stewart WF, Diamond S, Diamond ML, Reed M. Prevalence and burden of migraine in the United States: Data from the American Migraine Study II. Headache 2001;41(7):646-57.

15. Molgaard CA, Rothrock J, Stang PE, Golbeck AL. Prevelence of migraine among Mexican Americans in San Diego, California. Headache 2002;42(9):878-82.

16. Baykan B, Ertas M, Karli N, et al. The burden of headache in neurology outpatient clinics in Turkey. Pain Pract 2007;7(4):313-23.

17. Koseoglu E, Nacar M, Talaslioglu A, Cetinkaya F. Epidemiological and clinical characteristics of migraine and tension type headache in 1146 females in Kayseri, Turkey. Cephalalgia 2003;23(5):381-8.

18. Bank J, Marton S. Hungarian migraine epidemiyology. Headache 2000;40(2):164-9.

19. Rasmussen BK, Olesen J: Migraine with aura and without aura: An epidemiological study. Cephalalgia 1992;12(4):221-8.

20. Mathew NT. Migraine. In: Evans RW, Mathew NT (ed). Handbook of Headache. 2nd ed. Philadelphia, USA: Lippincott Williams \& Wilkins; 2005:28-88

21. Russel MB, Iselius L, OlesenJ. Migraine without aura and migraine with aura are inherited disorders. Cephalalgia 1996;16(5):305-9.

22. Murtaza M, Kisat M, Daniel H, Sonawalla $A B$. Classification and clinical features of headache disorders in Pakistan: a retrospective review of clinical data. PLoS One 2009;4(6):5827.

23. Stewart WF, Bigal ME, Kolodner K, Dowson A, Liberman JN, Lipton RB. Familial risk of migraine: variation by proband age at onset and headache severity. Neurology. 2006;66(3):344-8.

24. Kelman L. The triggers or precipitants of the acute migraine attack. Cephalalgia 2007;27(5):394-402. 
25. Buse DC, Manack AN, Fanning KM, et al. Chronic migraine prevalence, disability and sociodemographic factors: results from the American Migraine Prevalence and Prevention Study. Headache 2012;52(10):1456-70.

26. Hagen K, Vatten L, Stovner LJ, Zwart JA, Krokstad S, Bovim G. Low socio-economic status is associated with increased risk of frequent headache: A prospective study of 22718 adults in Norway. Cephalalgia 2002; 22(8):672-79.

27. Manack A, Buse DC, Lipton RB. Chronic migraine: Epidemiology and disease burden. Curr Pain Headache Rep 2011;15(1):70-8.

28. Türkiye İstatistik Kurumu Haber Bülteni. İllerde yaşam indeksi, 2015 (updated 22 Jan 2016; cited: 20 Jun 2016). Available from: http://www.tuik.gov.tr. 